BMJ Open

Diabetes

Research

\& Care

\title{
Therapeutic efficacy and safety of initial triple combination of metformin, sitagliptin, and lobeglitazone in drug- naive patients with type 2 diabetes: initial triple study
}

\author{
Soo Lim (D) , ${ }^{1}$ Eu Jeong Ku (D) , , ${ }^{1,2}$ Seo Young Lee, ${ }^{1,3}$ Ji Hyun Lee, ${ }^{1,4}$ Jie-Eun Lee, \\ Kyoung Min Kim, ${ }^{1}$ Melanie J Davies ${ }^{6}$
}

To cite: Lim S, Ku EJ, Lee SY, et al. Therapeutic efficacy and safety of initial triple combination of metformin, sitagliptin, and lobeglitazone in drug-naïve patients with type 2 diabetes: initial triple study. BMJ Open Diab Res Care 2020;8:e000807. doi:10.1136/ bmjdrc-2019-000807

- Additional material is published online only. To view please visit the journal online (http://dx.doi.org/10.1136/ bmjdrc-2019-000807).

Parts of this study were presented at the 77th Scientific Sessions of the American Diabetes Association, San Diego, CA, 9-13 June 2017.

Received 7 August 2019 Revised 26 November 2019 Accepted 15 December 2019

Check for updates

C Author(s) (or their employer(s)) 2020. Re-use permitted under CC BY-NC. No commercial re-use. See rights and permissions. Published by BMJ.

For numbered affiliations see end of article.

Correspondence to Professor Soo Lim; limsoo@snu.ac.kr

\section{ABSTRACT}

Objective To compare the efficacy and safety of an initial triple therapy using metformin, a dipeptidyl peptidase-4 (DPP4) inhibitor, and thiazolidinedione with a stepwise approach using sulfonylurea and metformin in new-onset, drug-naïve patients with type 2 diabetes.

Research design and methods Among drug-naïve patients with $9.0 \%-12.0 \%$ glycated hemoglobin $(\mathrm{HbA1c})$ but no hyperglycemic symptoms, 100 subjects who started triple medications (metformin $1000 \mathrm{mg} /$ day, sitagliptin $100 \mathrm{mg} /$ day, and lobeglitazone $0.5 \mathrm{mg} /$ day) were selected as an initial triple therapy group. Age and body mass index-matched subjects $(n=100)$ who started glimepiride ( $\geq 2 \mathrm{mg} /$ day with uptitration) and metformin $(\geq 1000 \mathrm{mg} /$ day with uptitration) were selected as a conventional therapy group. We investigated changes in $\mathrm{HbA1c}$ level, dynamic indexes for insulin sensitivity and $\beta$-cell function, and hypoglycemia.

Results After 12 months of treatment, $\mathrm{HbA} 1 \mathrm{c}$ levels decreased significantly in both groups: from $10.7 \% \pm 1.0 \%$ to $6.7 \% \pm 1.3 \%$ in the triple group, and from $10.5 \% \pm 1.0 \%$ to $7.3 \% \pm 1.2 \%$ in the conventional therapy group. At 12 months, achievement of the $\mathrm{HbA} 1 \mathrm{C}$ target $(<7.0 \%)$ was higher in the triple group than in the conventional group $(70 \%$ vs $52 \%, p<0.01)$. Dynamic indexes related to $\beta$-cell function and insulin sensitivity improved, and albuminuria reduced significantly only in the triple group. Hypoglycemia was more common in the conventional group.

Conclusions Initial triple combination therapy with the DPP4 inhibitor, metformin, and thiazolidinedione showed a higher achievement of the target $\mathrm{HbA} 1 \mathrm{c}$ goal with a lower risk of hypoglycemia, better restoration of $\beta$-cell function, and multiple metabolic benefits, implying durable glycemic control. This strategy may be useful for patients presenting with type 2 diabetes and high HbA1c levels.

\section{INTRODUCTION}

Landmark clinical trials in the management of type 2 diabetes (T2D) including the UK Prospective Diabetes Study (UKPDS), the Action to Control Cardiovascular Risk in Diabetes Study, Action in Diabetes and

\section{Significance of this study}

What is already known about this subject?

- Early combination therapy with incretin-based therapy and/or thiazolidinedione (TZD) has been proven better for glycemic control than metformin and sulfonylurea.

- A study using initial triple combination with metformin, pioglitazone, and exenatide showed significantly better long-term glycemic control than a stepwise approach using metformin, sulfonylurea, and insulin.

What are the new findings?

- Initial combination treatment with metformin, sitagliptin, and lobeglitazone (a new TZD) showed better efficacy and less hypoglycemia compared with a conventional approach of sequential dose escalation with metformin and sulfonylurea in drug-naïve patients with type 2 diabetes (T2D) with high baseline HbA1c levels $(9.0 \%-12.0 \%)$.

How might these results change the focus of research or clinical practice?

- Triple combination therapy with dipeptidyl peptidase- 4 inhibitor to preserve $\beta$-cells and with TZD and metformin to lower the burden on the $\beta$-cells might be a good option for drug-naïve patients with T2D with high HbA1c levels.

Vascular Disease: Preterax and Diamicron MR Controlled Evaluation, and the Veterans Affairs Diabetes Trial have shown that intensive glycemic control reduces the risk for microvascular complications. ${ }^{1-4}$ In addition, intensive glycemic control in the early period of diabetes results in a significantly lower incidence of cardiovascular disease and mortality. ${ }^{4}$ Additionally, international consensus recognizes the need for combination therapy for glucose lowering in those patients significantly above the glycated 
hemoglobin (HbA1c) target. ${ }^{5}$ International and local clinical guidelines propose glycemic targets as HbAlc level $<7.0 \%$ in general, and a more stringent target $(6.0 \%-6.5 \%)$ in patients whose duration of diabetes was shorter, free from vascular complications, or who were young. ${ }^{6-8}$

Progressive $\beta$-cell failure under an insulin-resistant milieu has limited long-term durable glycemic control in patients with T2D, ${ }^{9}$ which leads to increased risk for microvascular and macrovascular complications. ${ }^{10}$ In the UKPDS, $>70 \%$ of patients who were treated with sulfonylurea or insulin eventually failed to achieve the target HbAlc level $(<7.0 \%)$ over 9 years. ${ }^{11}$ By contrast, thiazolidinediones (TZD), peroxisome proliferator-activated receptor- $\gamma$ (PPAR- $\gamma$ ) agonists, have shown more durable glycemic control than sulfonylurea. ${ }^{12}{ }^{13}$ PPAR- $\gamma$ is a nuclear hormone receptor that regulates glucose homeostasis, lipid metabolism, and adipocyte function. ${ }^{14}$ TZDs target PPAR- $\gamma$ and have shown many beneficial effects in metabolic profiles. However, TZD therapy is associated with some adverse events, which limit its tolerability.

Several new antihyperglycemic agents, such as dipeptidyl peptidase-4 (DPP4) inhibitors, glucagon-like peptide-1 receptor (GLP1R) agonists, and sodium/ glucose cotransporter-2 (SGLT2) inhibitors, have been developed. Investigation of whether combination therapy with these new classes of different antidiabetic medications results in favorable glycemic control is warranted.

There is some evidence for initial combination therapy due to the greater initial reduction of HbAlc than can be provided by metformin alone. ${ }^{1516}$ A study using initial triple combination with metformin, pioglitazone, and exenatide, a GLP1R agonist, showed significantly better long-term glycemic control than a stepwise approach using metformin, sulfonylurea, and insulin. ${ }^{17}$ However, more evidence is required to confirm that a triple combination approach is superior to sequential addition of medications for maintaining glycemic control or slowing the progression of diabetes.

We therefore investigated the efficacy and safety of initial triple combination therapy with oral agents: metformin, sitagliptin (a DPP4 inhibitor), and lobeglitazone (a TZD). Sitagliptin increases GLP1 levels by inhibiting DPP4 enzyme activity, potentiates glucosedependent insulin secretion, and lowers glucagon secretion. ${ }^{18}$ Lobeglitazone is a new TZD and has similar glucose-lowering efficacy to pioglitazone. ${ }^{19}$ We believe that the mechanism of action of these drugs is complementary to that of metformin and to each other, and all involve a low risk of hypoglycemia, suggesting an additive effect in glucose control and safety.

\section{PATIENTS AND METHODS}

\section{Study design}

Among new-onset, drug-naïve participants with T2D who visited the diabetes clinic, Seoul National University Bundang Hospital in 2014-2016, we selected 322 who met the following criteria for this study. Inclusion criteria were: (1) age $\geq 20$ years; (2) patients with an HbA1c level of 9.0\%-12.0\% at diagnosis; (3) absence of severe hyperglycemic symptoms; and (4) negative pregnancy tests. Among them, 31 patients were excluded for the following exclusion criteria: (1) severe hyperglycemic symptoms, such as weight loss $>5 \mathrm{~kg}$; (2) previous use of oral hypoglycemic agents or insulin within 6 months; (3) type 1 diabetes, which was diagnosed by a fasting C-peptide level of $<0.3 \mathrm{ng} / \mathrm{mL}$ or positivity for glutamic acid decarboxylase antibody; (4) gestational diabetes; (5) a secondary cause of diabetes; (6) renal insufficiency (estimated glomerular filtration rate $<50 \mathrm{~mL} / \mathrm{min} / 1.73 \mathrm{~m}^{2}$ ); (7) heart failure (New York Heart Association class IIIIV); or (8) a history of malignancy or chronic disease.

Among these 291 patients with T2D who met the inclusion and exclusion criteria, 100 who started initial triple combination therapy, metformin $1000 \mathrm{mg} /$ day, sitagliptin $100 \mathrm{mg} /$ day, and lobeglitazone $0.5 \mathrm{mg} /$ day at baseline were selected consecutively for the initial triple therapy group. Using age ( \pm 3 years) and body mass index (BMI) $\left( \pm 2 \mathrm{~kg} / \mathrm{m}^{2}\right)$ matching, another 100 subjects who started glimepiride (2-6 mg/day) and metformin (1000$2000 \mathrm{mg}$ /day) at baseline were selected as a conventional stepwise therapy group: initial doses of glimepiride and metformin were decided at the physician's discretion.

In the triple therapy group, if the HbAlc level was $>8.0 \%$ at 2 and 5 months, the metformin dose was recommended to increase by $25 \%-50 \%$ at the physician's discretion. If the $\mathrm{HbA1c}$ level was still $>7.0 \%$ at 8 months, the metformin dosage was recommended to be increased further at the physician's discretion. In the conventional group, if the HbA1c level was $>8.0 \%$ at 2 and 5 months, the metformin dose was increased by $25 \%-50 \%$ or the glimepiride dose was increased by $25 \%-50 \%$ if the metformin dose exceeded $2000 \mathrm{mg}$ /day. If the $\mathrm{HbAlc}$ level was still $>7.0 \%$ at 8 months, the metformin dose was further increased up to $2500 \mathrm{mg}$ /day and glimepiride up to $8 \mathrm{mg}$ /day. However, actual doses of metformin and glimepiride were titrated at each visit according to physician's discretion.

A third antihyperglycemic agent was prescribed to patients with a high HbA1c level $(>9.0 \%)$ at the physician's discretion at any follow-up visit. At every visit, compliance to the medications was assessed using the pill counting method.

\section{Follow-up examination}

At baseline and 2, 5, 8, and 12 months, body weight, fasting glucose, and HbA1c levels were measured (online supplementary figure S2). At baseline and 12 months, fasting levels of insulin, lipid profiles including total cholesterol, triglyceride, and high-density lipoprotein (HDL)-cholesterol and low-density lipoprotein (LDL)cholesterol, and albuminuria were measured. A $75 \mathrm{~g}$ standard oral glucose tolerance test (OGTT) was conducted at baseline and 12 months without taking antihyperglycemic agents. Liver enzyme activities, such as aspartate 
aminotransferase (AST) and alanine aminotransferase (ALT), and serum creatinine levels were measured at baseline, 5 , and 12 months.

Glucose monitoring at home (fasting and postprandial 2-hour state, at least twice a day) was recommended to all patients. At every visit, adverse events and hypoglycemia were evaluated using the records of home-measured glucose values and symptoms of hypoglycemia.

\section{Hypoglycemia and other adverse events}

Hypoglycemia (level 1) was defined as blood glucose concentration $<70 \mathrm{mg} / \mathrm{dL}(3.9 \mathrm{mmol} / \mathrm{L})$, with or without symptoms, or hypoglycemia symptoms that subsided after glucose ingestion. Severe hypoglycemia (level 2) was defined as blood glucose concentration $<54 \mathrm{mg}$ / $\mathrm{dL}(3.0 \mathrm{mmol} / \mathrm{L})$ or hypoglycemia requiring third-party assistance. Other adverse events, such as dizziness, headache, gastrointestinal discomfort, or edema, were also investigated at each visit.

\section{Study outcomes}

The primary outcome of this study was the change in HbA1c level from baseline after 12 months of treatment. Secondary outcomes included (1) changes in pancreatic $\beta$-cell function and insulin resistance, which were estimated by dynamic glycemic parameters including OGTT profile, (2) changes in lipid profiles and albuminuria, and (3) weight change. Safety outcomes included hypoglycemia and other adverse events.

\section{Anthropometry and biochemistry}

Height and body weight were measured by standard methods with the subjects in light clothing. BMI was calculated as weight (in kilograms) divided by height (in meters) squared. After 10 hours of overnight fasting, venous blood samples were taken for biochemistry assays. Plasma glucose concentration was measured using a glucose oxidase method (747 Clinical Chemistry Analyzer; Hitachi, Tokyo, Japan). HbA1c was measured using a Bio-Rad Variant II Turbo HPLC Analyzer (BioRad, Hercules, CA, USA) in a National Glycohemoglobin Standardization Program level II certified laboratory. Fasting plasma C-peptide and insulin levels were measured by radioimmunoassay (Linco, St Louis, MO, USA). AST/ALT and serum creatinine were measured using an Architect Ci8200 analyzer (Abbott Laboratories, Abbott Park, IL, USA). Serum-free fatty acid, total cholesterol, triglyceride, HDL-cholesterol, and LDL-cholesterol levels were measured using a 747 Clinical Chemistry Analyzer (Hitachi). Urinary albumin was measured using turbidimetry (502X, A\&T, Tokyo, Japan), and urinary creatinine was measured using the Jaffe method (Hitachi 7170 , Hitachi). The ratio of urinary albumin to creatinine concentration $(\mathrm{mg} / \mathrm{g})$ was used for albuminuria.

All subjects underwent a standardized $75 \mathrm{~g}$ OGTT with overnight fasting for 10 hours. The levels of plasma glucose, insulin, and C-peptide were measured at baseline and at $30 \mathrm{~min}$ and 2 hours after the OGTT.
To estimate pancreatic $\beta$-cell function and insulin resistance, several surrogate markers were calculated: the homeostasis model assessment of insulin resistance (HOMA-IR) and $\beta$-cell function (HOMA- $\beta$ ), ${ }^{20}$ the Matsuda index,${ }^{21}$ the quantitative insulin sensitivity check index (QUICKI) ${ }^{22}$ the insulinogenic index (IGI), and the disposition index. The disposition index was calculated by IGI multiplied by the Matsuda index and it was validated in both people with European ancestry and Asians. ${ }^{2324}$ The total area under the curve of glucose and insulin $\left(\mathrm{AUC}_{\text {glucose }}\right.$ and $\left.\mathrm{AUC}_{\text {insulin }}\right)$ were also derived from the results of the OGTT. The IGI30 was calculated as the ratio of the $30 \mathrm{~min}$ insulin level minus the fasting insulin level to that of the $30 \mathrm{~min}$ glucose level minus the fasting glucose level ( $\Delta$ Insulin30: $\Delta$ Glucose 30$)^{25}$ and it was validated against first-phase insulin secretion on intravenous glucose tolerance testing. ${ }^{26}$ In addition, the IGI120 was calculated as the ratio of the $120 \mathrm{~min}$ insulin level minus the fasting insulin to that of the $120 \mathrm{~min}$ glucose level minus the fasting glucose level ( $\Delta$ Insulin120: $\Delta$ Glucose120) for all insulin secretion, based on the OGTT results.

\section{Statistical analysis}

Values are presented as the mean $\pm \mathrm{SD}$. Two-sided t-tests were used to compare mean differences between treatment arms and a $\chi^{2}$ test was used to test the significance of discrete variables. To test for the independent association of intervention with glycemic target goal achievement, we performed a multivariable logistic regression model for patients without hypoglycemia and with $\mathrm{HbAlc}<7.0 \%$.

The study was powered to detect a $0.5 \%( \pm 0.95 \mathrm{SD})$ HbA1c difference between treatment arms based on the $\mathrm{HbA1c}$ decrease in previous studies including the PROactive study. ${ }^{1727}$ Based on this assumption, we hypothesized that participants who received initial triple therapy with metformin, TZD, DPP4 inhibitor combination would achieve a $\geq 0.5 \%$ lower HbAlc without hypoglycemia than those receiving conventional dual stepwise therapy with metformin and sulfonylurea. We calculated that 96 participants per arm would provide $90 \%$ power to detect a $0.5 \% \mathrm{HbAlc}$ difference without hypoglycemia between treatment arms at $\alpha<0.05$.

\section{RESULTS}

\section{Subject characteristics}

In total, 322 subjects with newly diagnosed T2D were screened in 2014-2016. Among them, 100 patients were selected as an initial triple therapy group with metformin, TZD, and a DPP4 inhibitor, and another 100 patients as a conventional stepwise therapy group with metformin and sulfonylurea (online supplementary figure S1). The demographic and biochemical characteristics of the subjects are shown in table 1 . The mean age and BMI of the study subjects were 50.4-52.4 years $( \pm 10.9 \mathrm{SD})$ and $25.7 \mathrm{~kg} / \mathrm{m}^{2}( \pm 3.5-4.8 \mathrm{SD})$ in both groups, which is a typical pattern found in Asian patients with T2D. 
Table 1 Baseline characteristics of the study populations

\begin{tabular}{|c|c|c|c|}
\hline & $\begin{array}{l}\text { Initial triple } \\
\text { therapy } \\
(n=100)\end{array}$ & $\begin{array}{l}\text { Conventional } \\
\text { stepwise } \\
\text { therapy } \\
(n=100)\end{array}$ & $P$ value \\
\hline $\begin{array}{l}\text { Gender (male/ } \\
\text { female) }\end{array}$ & $65 / 35$ & $67 / 33$ & NS \\
\hline Family history of DM & 53 (53.0\%) & 46 (46.0\%) & NS \\
\hline History of CVD & $7(7.0 \%)$ & $10(10.0 \%)$ & NS \\
\hline Age (years) & $50.4 \pm 10.9$ & $52.2 \pm 10.9$ & NS \\
\hline Height (cm) & $166.5 \pm 8.2$ & $166.2 \pm 9.1$ & NS \\
\hline Body weight (kg) & $71.6 \pm 15.8$ & $71.2 \pm 12.9$ & NS \\
\hline $\begin{array}{l}\text { Body mass index } \\
\left(\mathrm{kg} / \mathrm{m}^{2}\right)\end{array}$ & $25.7 \pm 4.8$ & $25.7 \pm 3.5$ & NS \\
\hline SBP (mm Hg) & $131.8 \pm 17.7$ & $132.8 \pm 16.0$ & NS \\
\hline DBP (mm Hg) & $80.4 \pm 12.3$ & $81.1 \pm 11.7$ & NS \\
\hline $\begin{array}{l}\text { Duration of DM } \\
\text { (months) }\end{array}$ & $35.4 \pm 59.7$ & $27.6 \pm 49.6$ & NS \\
\hline HbA1c (\%) & $10.8 \pm 0.9$ & $10.6 \pm 1.0$ & NS \\
\hline $\begin{array}{l}\text { Fasting plasma } \\
\text { glucose (mg/dL) }\end{array}$ & $226.9 \pm 62.1$ & $225.3 \pm 69.2$ & NS \\
\hline $\begin{array}{l}\text { Postload } 30 \mathrm{~min} \\
\text { glucose (mg/dL) }\end{array}$ & $319.4 \pm 71.2$ & $314.7 \pm 65.2$ & NS \\
\hline $\begin{array}{l}\text { Postload } 120 \mathrm{~min} \\
\text { glucose (mg/dL) }\end{array}$ & $364.7 \pm 86.0$ & $357.1 \pm 87.2$ & NS \\
\hline $\begin{array}{l}\text { Fasting plasma } \\
\text { insulin }(\mu l \mathrm{U} / \mathrm{mL})\end{array}$ & $11.1 \pm 6.1$ & $10.8 \pm 5.9$ & NS \\
\hline $\begin{array}{l}\text { Postload } 30 \mathrm{~min} \\
\text { insulin }(\mu \mathrm{IU} / \mathrm{mL})\end{array}$ & $16.7 \pm 11.2$ & $15.8 \pm 7.2$ & NS \\
\hline $\begin{array}{l}\text { Postload } 120 \mathrm{~min} \\
\text { insulin ( } \mu \mathrm{IU} / \mathrm{mL})\end{array}$ & $20.8 \pm 19.1$ & $20.5 \pm 16.6$ & NS \\
\hline C-peptide (ng/mL) & $2.3 \pm 1.4$ & $2.5 \pm 1.4$ & NS \\
\hline Glucagon (pg/mL) & $194.0 \pm 72.4$ & $198.5 \pm 89.8$ & NS \\
\hline $\begin{array}{l}\text { Total cholesterol } \\
\text { (mg/dL) }\end{array}$ & $210.6 \pm 43.5$ & $206.7 \pm 54.4$ & NS \\
\hline Triglyceride (mg/dL) & $205.4 \pm 188.1$ & $190.7 \pm 170.6$ & NS \\
\hline $\begin{array}{l}\text { HDL-cholesterol } \\
\text { (mg/dL) }\end{array}$ & $47.6 \pm 9.7$ & $49.2 \pm 11.9$ & NS \\
\hline $\begin{array}{l}\text { LDL-cholesterol } \\
\text { (mg/dL) }\end{array}$ & $125.3 \pm 33.5$ & $123.8 \pm 39.9$ & NS \\
\hline $\begin{array}{l}\text { Free fatty acid } \\
(\mu \mathrm{mol} / \mathrm{L})\end{array}$ & $590.7 \pm 208.2$ & $684.6 \pm 191.4$ & NS \\
\hline AST (IU/L) & $26.9 \pm 13.7$ & $27.6 \pm 15.9$ & NS \\
\hline ALT (IU/L) & $34.8 \pm 27.6$ & $34.9 \pm 27.9$ & NS \\
\hline $\begin{array}{l}\text { Serum creatinine } \\
\text { (mg/dL) }\end{array}$ & $0.77 \pm 0.20$ & $0.78 \pm 0.20$ & NS \\
\hline $\begin{array}{l}\text { Urinary albumin- } \\
\text { creatinine ratio } \\
(\mathrm{mg} / \mathrm{g})\end{array}$ & $109.1 \pm 328.0$ & $103.2 \pm 284.5$ & NS \\
\hline
\end{tabular}

\section{Comorbidity, $\mathbf{n}(\%)$}

\begin{tabular}{crrc} 
Hypertension & $32(32.0)$ & $34(34.0)$ & NS \\
ARB/ACE inhibitor $24(24.0)$ & $30(30.0)$ & NS \\
\hline & & Continued
\end{tabular}

Table 1 Continued

\begin{tabular}{clll}
\hline & $\begin{array}{l}\text { Initial triple } \\
\text { therapy } \\
(\mathbf{n = 1 0 0 )}\end{array}$ & $\begin{array}{l}\text { Conventional } \\
\text { stepwise } \\
\text { therapy } \\
(\mathbf{n}=100)\end{array}$ & P value \\
\hline Dyslipidemia & $72(72.0)$ & $68(68.0)$ & NS \\
\hline Statin therapy & $38(38.0)$ & $42(42.0)$ & NS \\
\hline Fibrate therapy & $3(3.0)$ & $4(4.0)$ & NS \\
\hline
\end{tabular}

Data are expressed as the mean $\pm S D$. $P$ values were calculated using Student's t-tests for continuous data and $\chi^{2}$ tests for categorical data.

ALT, alanine aminotransferase; ARB, angiotensin-II receptor blocker; AST, aspartate aminotransferase; CVD, cardiovascular disease; DBP, diastolic blood pressure; DM, diabetes mellitus; HDL, high-density lipoprotein; LDL, lowdensity lipoprotein; NS, not significant; SBP, systolic blood pressure.

Around $40 \%$ of patients in the two groups were taking statins at the baseline in this study, most of them of mild to moderate intensity. During the study period, four patients in the triple group and three patients in the conventional group received a new prescription of moderate-intensity statins. The proportion of patients who were taking antihypertensive drugs was $32.0 \%$ in the initial group and $34.0 \%$ in the conventional group.

\section{Disposition of subjects}

Of 100 participants in the triple group, 14 discontinued follow-up (online supplementary figure S1). Reasons for discontinuation were: hypoglycemia $(n=1)$, other adverse events $(n=4)$, and missing in the follow-up visit without prior notice $(n=9)$; these nine patients explained that their blood glucose levels were well controlled, and they did not feel the need to continue in the study. Of 100 participants in the conventional group, 16 discontinued follow-up. Reasons for discontinuation were: hypoglycemia $(n=5)$, poor compliance $(n=1)$, other adverse events $(\mathrm{n}=5)$, and missing in the follow-up visit without prior notice $(\mathrm{n}=5)$.

Drug compliance was $>85 \%$ in both groups. The metformin dose was increased slightly from $1035 \mathrm{mg} /$ day at baseline to $1194 \mathrm{mg} /$ day at the end of the study in the initial triple group ( $>0.05)$. The metformin dose was increased significantly from $1030 \mathrm{mg}$ /day at baseline to $1425 \mathrm{mg}$ /day at the end of study period in the conventional treatment group $(\mathrm{p}<0.05)$. The glimepiride dose was increased from $4.34 \mathrm{mg} /$ day at baseline to $4.51 \mathrm{mg} /$ day at 12 months in the conventional treatment group. Note that the glimepiride dose was decreased in 10 patients in the conventional group to prevent hypoglycemia. Basal insulin as a rescue therapy was given to five patients in the conventional group. As prespecified, a total of $86(86 \%)$ patients in the triple group and 84 $(84 \%)$ in the conventional group were included in the final analysis. 

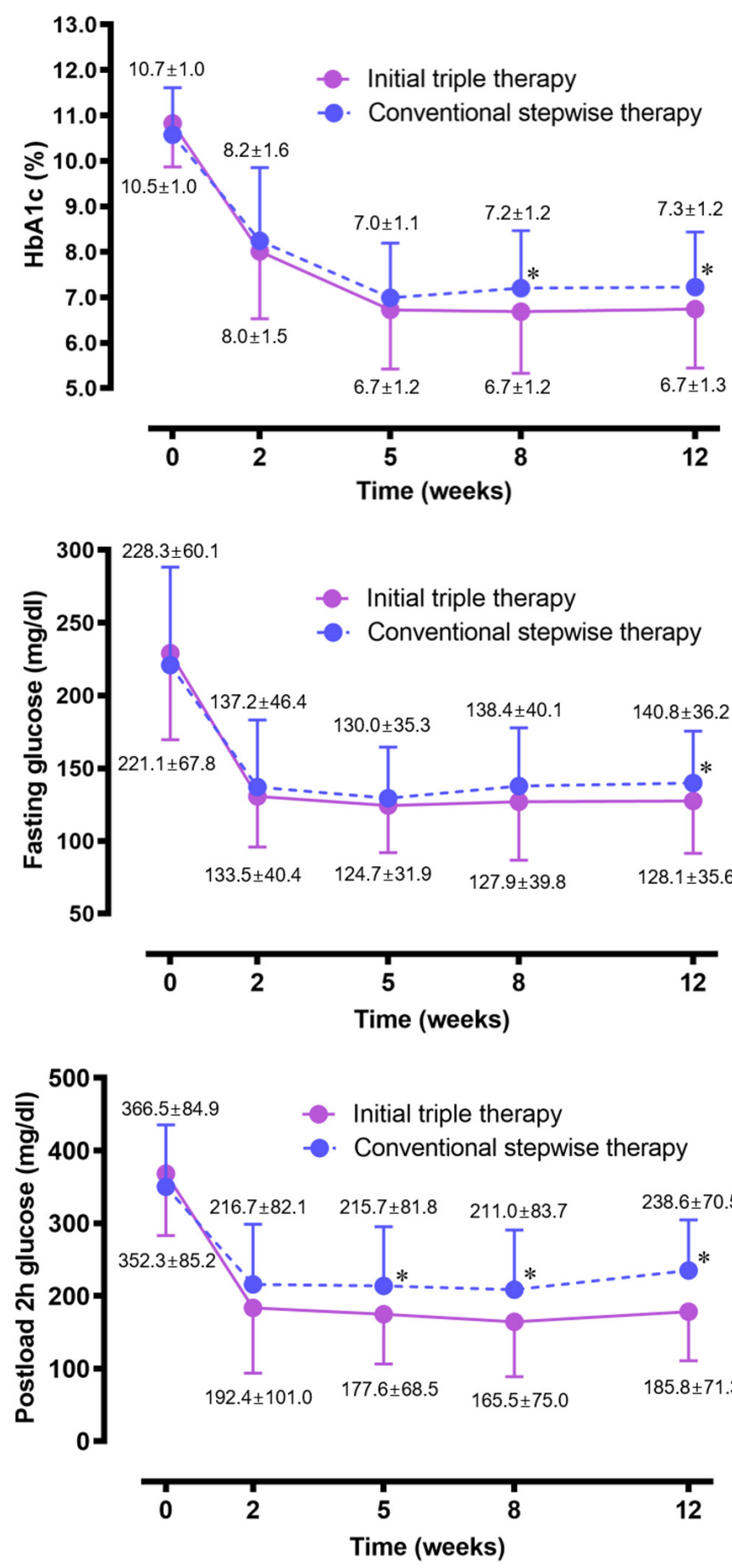

Figure 1 Changes in $\mathrm{HbA} 1 \mathrm{c}$ and fasting and postload 2-hour glucose concentrations at baseline and 2, 5, 8, and 12 months of follow-up. Student's t-test was used for comparison between the two groups. ${ }^{*} \mathrm{P}<0.05$.

\section{Study outcomes}

HbA1c levels at baseline, 2, 5, 8, and 12 months between the two treatment groups are shown in figure 1. Baseline HbAlc levels did not differ between the groups that received 1 year treatment: $10.7 \% \pm 1.0 \%$ in the triple group versus $10.5 \% \pm 1.0 \%$ in the conventional group; at 5 months, HbAlc levels decreased significantly in both groups: $6.7 \% \pm 1.2 \%$ vs $7.0 \% \pm 1.1 \%$, respectively, but there was no significant difference between the two groups. At 8 months, HbAlc levels slightly increased with conventional therapy to $7.2 \% \pm 1.2 \%$, but remained stable at $6.7 \% \pm 1.2 \%$ with triple therapy; thus, the difference in $\mathrm{HbA1c}$ between the two treatments progressively increased with time and was significantly different at 12 months: $6.7 \% \pm 1.3 \%$ vs $7.3 \% \pm 1.2 \%$; $p<0.001$. At 12 months, HbAlc levels decreased by $4.05 \% \pm 1.70 \%$ in participants receiving the triple therapy and $3.28 \% \pm 1.57 \%$ in the conventional group $(\mathrm{p}<0.05)$.

The baseline fasting glucose concentrations in patients in the triple group and in those in the conventional group were similar. At 12 months, the fasting glucose level was lower in the patients in the triple group than in those in the conventional group: $128.1 \pm 35.6 \mathrm{mg} / \mathrm{dL}(6.6 \pm 0.2 \mathrm{mmol} / \mathrm{L})$ vs $140.8 \pm 36.2 \mathrm{mg} /$ $\mathrm{dL}(7.2 \pm 0.3 \mathrm{mmol} / \mathrm{L}) ; \mathrm{p}<0.01$. The postprandial 2-hour glucose level also decreased in both groups at 2 months, but the gap in the level between the two groups became wider from 5 months. At 5, 8, and 12 months, the difference reached statistical significance.

Body weight and BMI in both groups increased significantly $\left(2.4 \mathrm{~kg}\right.$ and $0.8 \mathrm{~kg} / \mathrm{m}^{2}$ in the triple therapy group and $2.2 \mathrm{~kg}$ and $0.8 \mathrm{~kg} / \mathrm{m}^{2}$ in the conventional group, respectively) and this seemed to result from the restoration of glucose homeostasis after antihyperglycemic treatment. Specifically, TZD in the triple therapy group and sulfonylurea in the conventional group might contribute to the weight gain observed.

The participants who received the triple therapy showed a higher achievement rate in glycemic target goal than did those receiving conventional therapy at 12 months: $69.8 \%$ vs $52.4 \%$ in $\mathrm{HbA} 1 \mathrm{c}<7.0 \%$, $\mathrm{p}=0.027 ; 58.1 \%$ vs $36.9 \%$ in $\mathrm{HbAlc} \leq 6.5 \%, \mathrm{p}=0.006$ (figure $2 \mathrm{~A}$ ). The proportion of participants who achieved the glycemic target goal without hypoglycemia was higher in the triple group than in the conventional group: $69.8 \%$ vs $41.7 \%$ in
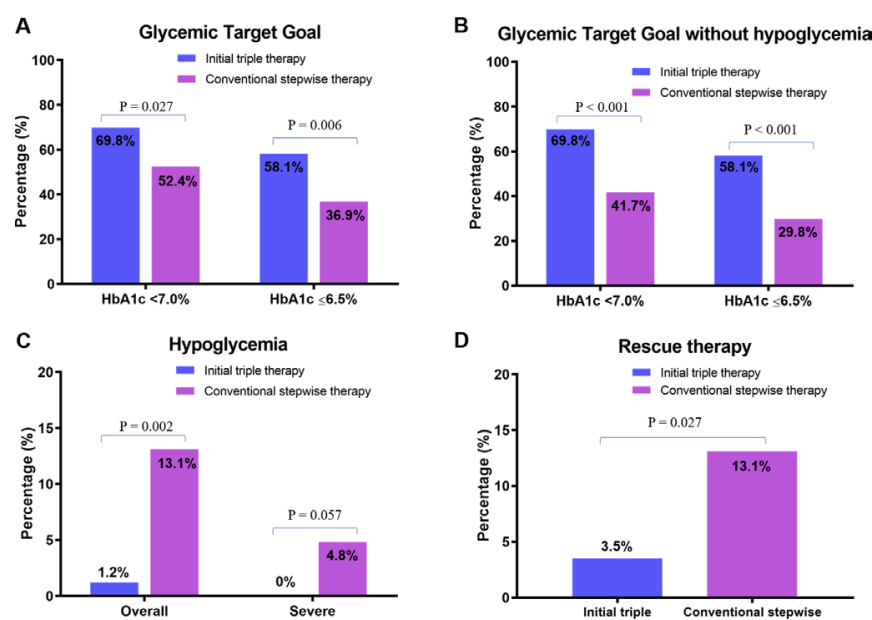

Figure 2 Overall glycemic target goal achievement (A), glycemic target goal achievement without hypoglycemia (B), percentage of patients who experienced hypoglycemia and severe hypoglycemia (C), and percentage of patients who received rescue therapy (D) among the participants who completed the 12 months' follow-up. 
Table 2 Changes in anthropometric parameters and biomarkers after treatment

Initial triple therapy $(n=86)$

Conventional stepwise therapy $(n=84)$

\begin{tabular}{|c|c|c|c|c|c|c|c|}
\hline & Baseline & 12 months & $P$ value & Baseline & 12 months & $P$ value & P value* \\
\hline Body mass index $\left(\mathrm{kg} / \mathrm{m}^{2}\right)$ & $25.9 \pm 4.9$ & $26.7 \pm 4.8$ & $<0.01$ & $25.6 \pm 3.6$ & $26.4 \pm 3.7$ & $<0.01$ & NS \\
\hline $\mathrm{SBP}(\mathrm{mm} \mathrm{Hg})$ & $131.0 \pm 17.6$ & $131.3 \pm 16.7$ & NS & $132.0 \pm 15.8$ & $135.2 \pm 17.0$ & NS & NS \\
\hline $\mathrm{DBP}(\mathrm{mm} \mathrm{Hg})$ & $79.9 \pm 12.8$ & $78.1 \pm 10.8$ & NS & $79.7 \pm 11.2$ & $79.7 \pm 11.7$ & NS & NS \\
\hline $\mathrm{HbA1c}(\%)$ & $10.7 \pm 1.0$ & $6.7 \pm 1.3$ & $<0.01$ & $10.5 \pm 1.0$ & $7.3 \pm 1.2$ & $<0.01$ & $<0.05$ \\
\hline $\begin{array}{l}\text { Fasting plasma glucose } \\
(\mathrm{mg} / \mathrm{dL})\end{array}$ & $228.3 \pm 60.1$ & $128.1 \pm 35.6$ & $<0.01$ & $221.1 \pm 67.8$ & $140.8 \pm 36.2$ & $<0.01$ & $<0.05$ \\
\hline $\begin{array}{l}\text { Postload } 30 \text { min glucose } \\
\text { (mg/dL) }\end{array}$ & $318.3 \pm 69.2$ & $185.9 \pm 49.8$ & $<0.01$ & $314.1 \pm 67.6$ & $238.1 \pm 28.9$ & 0.068 & $<0.05$ \\
\hline $\begin{array}{l}\text { Postload } 120 \text { min glucose } \\
\text { (mg/dL) }\end{array}$ & $366.5 \pm 84.9$ & $185.8 \pm 71.3$ & $<0.01$ & $352.3 \pm 85.2$ & $238.6 \pm 70.5$ & $<0.01$ & $<0.05$ \\
\hline $\mathrm{AUC}_{\text {glucose }}$ & $308.9 \pm 64.5$ & $165.2 \pm 40.2$ & $<0.01$ & $309.3 \pm 58.2$ & $237.3 \pm 43.9$ & $<0.01$ & $<0.05$ \\
\hline $\begin{array}{l}\text { Fasting plasma insulin }(\mu \mathrm{lU} / \\
\mathrm{mL})\end{array}$ & $10.8 \pm 6.1$ & $9.4 \pm 5.0$ & NS & $10.4 \pm 5.5$ & $10.9 \pm 5.1$ & NS & NS \\
\hline $\begin{array}{l}\text { Postload } 30 \text { min insulin ( } \mu \mathrm{IU} / \\
\mathrm{mL} \text { ) }\end{array}$ & $15.7 \pm 9.0$ & $25.4 \pm 12.6$ & $<0.01$ & $15.6 \pm 7.4$ & $12.6 \pm 3.3$ & NS & $<0.05$ \\
\hline $\begin{array}{l}\text { Postload } 120 \text { min insulin } \\
(\mu \mathrm{lU} / \mathrm{mL})\end{array}$ & $20.7 \pm 20.1$ & $46.3 \pm 47.4$ & $<0.01$ & $19.8 \pm 17.1$ & $16.8 \pm 5.8$ & NS & $<0.05$ \\
\hline$A \cup C_{\text {insulin }}$ & $15.8 \pm 9.7$ & $26.7 \pm 17.9$ & $<0.01$ & $14.8 \pm 7.9$ & $12.9 \pm 3.5$ & NS & $<0.05$ \\
\hline C-peptide (ng/mL) & $2.2 \pm 1.3$ & $2.5 \pm 1.0$ & NS & $2.6 \pm 1.4$ & $3.1 \pm 1.6$ & NS & NS \\
\hline HOMA-IR† & $6.1 \pm 3.7$ & $2.7 \pm 1.5$ & $<0.01$ & $5.7 \pm 3.4$ & $4.5 \pm 2.4$ & NS & $<0.05$ \\
\hline HOMA- $\beta \dagger$ & $27.2 \pm 18.7$ & $81.1 \pm 66.1$ & $<0.01$ & $31.1 \pm 28.8$ & $43.1 \pm 26.5$ & NS & $<0.05$ \\
\hline QUICKI & $0.50 \pm 0.07$ & $0.59 \pm 0.07$ & $<0.01$ & $0.50 \pm 0.08$ & $0.52 \pm 0.07$ & 0.029 & $<0.05$ \\
\hline Matsuda index & $4.35 \pm 2.55$ & $6.56 \pm 3.34$ & $<0.01$ & $4.91 \pm 3.03$ & $6.01 \pm 3.45$ & $<0.01$ & $<0.05$ \\
\hline IGI30 & $0.044 \pm 0.089$ & $0.298 \pm 0.263$ & $<0.01$ & $0.064 \pm 0.069$ & $0.050 \pm 0.063$ & NS & $<0.05$ \\
\hline IGI120 & $0.154 \pm 0.583$ & $0.481 \pm 1.893$ & $<0.01$ & $0.149 \pm 0.403$ & $0.070 \pm 0.053$ & NS & $<0.05$ \\
\hline Disposition index & $0.20 \pm 0.32$ & $1.96 \pm 2.55$ & $<0.01$ & $0.31 \pm 0.39$ & $0.25 \pm 0.29$ & NS & $<0.05$ \\
\hline Glucagon (pg/mL) & $194.0 \pm 76.0$ & $180.3 \pm 76.3$ & NS & $206.6 \pm 90.9$ & $210.5 \pm 106.1$ & NS & NS \\
\hline Total cholesterol (mg/dL) & $207.9 \pm 43.3$ & $178.1 \pm 38.3$ & $<0.01$ & $206.5 \pm 52.8$ & $172.6 \pm 40.5$ & $<0.01$ & NS \\
\hline Triglycerides (mg/dL) & $184.9 \pm 130.3$ & $144.1 \pm 81.3$ & $<0.01$ & $192.0 \pm 179.7$ & $171.4 \pm 117.4$ & NS & $<0.05$ \\
\hline HDL-cholesterol (mg/dL) & $46.9 \pm 9.4$ & $49.1 \pm 8.9$ & $<0.05$ & $50.0 \pm 12.1$ & $47.1 \pm 9.8$ & NS & $<0.05$ \\
\hline LDL-cholesterol (mg/dL) & $125.3 \pm 33.4$ & $100.5 \pm 30.5$ & $<0.01$ & $125.1 \pm 38.5$ & $96.7 \pm 30.3$ & $<0.01$ & NS \\
\hline Free fatty acid ( $\mu \mathrm{mol} / \mathrm{L})$ & $590.7 \pm 208.2$ & $396.3 \pm 150.7$ & NS & $684.6 \pm 191.4$ & $571.5 \pm 206.3$ & NS & NS \\
\hline AST (IU/L) & $26.5 \pm 13.2$ & $27.8 \pm 22.1$ & NS & $28.1 \pm 15.5$ & $33.4 \pm 21.9$ & $<0.05$ & $<0.05$ \\
\hline ALT (IU/L) & $34.3 \pm 29.1$ & $30.3 \pm 29.5$ & NS & $35.9 \pm 29.0$ & $41.6 \pm 33.6$ & NS & $<0.05$ \\
\hline Serum creatinine (mg/dL) & $0.76 \pm 0.19$ & $0.79 \pm 0.20$ & NS & $0.77 \pm 0.19$ & $0.81 \pm 0.29$ & NS & NS \\
\hline $\begin{array}{l}\text { Urinary albumin-creatinine } \\
\text { ratio }(\mathrm{mg} / \mathrm{g})\end{array}$ & $87.4 \pm 243.7$ & $72.8 \pm 278.8$ & $<0.05$ & $108.6 \pm 305.6$ & $114.9 \pm 388.2$ & NS & $<0.05$ \\
\hline
\end{tabular}

Data are expressed as mean $\pm S D$. $P$ values were calculated using a paired t-test between the values recorded at the baseline and after treatment.

*P values were calculated using Student's t-test for delta changes between the two groups.

†Log-transformed values were used for comparison.

ALT, alanine aminotransferase; AST, aspartate aminotransferase; AUC, area under the curve; DBP, diastolic blood pressure; HDL, highdensity lipoprotein; HOMA- $\beta$, homeostasis model assessment of $\beta$-cell function; HOMA-IR, homeostasis model assessment of insulin resistance; IGI, insulinogenic index; LDL, low-density lipoprotein; NS, not significant; QUICKI, quantitative insulin sensitivity check index; SBP, systolic blood pressure.

HbAlc $<7.0 \%, \mathrm{p}<0.001 ; 58.1 \%$ vs $29.8 \%$ in $\mathrm{HbA1c} \leq 6.5 \%$, $\mathrm{p}<0.001$ (figure $2 \mathrm{~B}$ ).

As secondary outcomes, HOMA- $\beta$ increased and HOMA-IR decreased significantly in patients in the triple group, but not in those in the conventional group (table 2). $\mathrm{AUC}_{\text {insulin }}$ increased significantly in patients in the triple group but did not change in those in the conventional group. The QUICKI, Matsuda index, 
IGI30, IGI120, and disposition index increased significantly in the triple group patients, while these indices did not change in those receiving the conventional therapy. There was a significant negative correlation between changes in HOMA- $\beta$ and changes in HbAlc levels $(\mathrm{r}=-0.501, \mathrm{p}<0.001)$, indicating a positive relationship between the improvement in $\beta$-cell function and the decrease in HbAlc concentration.

There were no significant differences in systolic or diastolic blood pressure changes between the two groups. Participants in both groups increased BMI by $0.8-0.9 \mathrm{~kg} /$ $\mathrm{m}^{2}$ at 5 months, which was maintained by 12 months. In the lipid profiles, triglyceride levels decreased and HDLcholesterol levels increased in participants in the triple group, but there was no significant change in the levels in the conventional group participants, resulting in a significant difference in levels between the two groups (table 2). The LDL-cholesterol levels decreased in both groups without significant difference between the two groups. The AST and ALT levels decreased in participants in the triple group but did not change or increased slightly in the conventional group, resulting in a significant difference between the two groups. The urinary albumin excretion rate decreased in participants in the triple group, but did not change in the conventional group, also resulting in a significant difference between the two groups (table 2).

In the multivariable linear regression analysis for the group of patients with $\mathrm{HbAlc}<7.0 \%$ but without hypoglycemia, we found that initial triple therapy showed a higher chance ( $\mathrm{OR}=2.776$ ) for achieving the target than conventional stepwise therapy (table 3). A short duration of diabetes mellitus was also found to be an independent variable for reaching the glycemic target. Patients with a high baseline C-peptide level also showed better achievement of target, but with only borderline significance $(\mathrm{p}=0.085)$.

Hypoglycemia, other adverse events, and rescue therapy In the group receiving triple therapy, one patient experienced hypoglycemia (figure 2C). In the conventional group, 11 patients experienced hypoglycemia including four with severe hypoglycemia, mostly with high doses of sulfonylurea. Among these 12 patients, one in the triple group and five in the conventional group discontinued the study because of hypoglycemia. A comparison of patients who received rescue therapy (figure 2D) identified three patients in the initial triple treatment group and 11 patients in the conventional group during the study period. Two patients received insulin therapy and one received an SGLT2 inhibitor in the initial triple therapy group. Four patients received insulin therapy and seven received DPP4 inhibitors in the conventional group as rescue therapy.

Except for hypoglycemia, most other adverse events were mild and non-specific (online supplementary table S1). The number of participants who withdrew from the study because of other adverse events was small: four from the triple group and five from the conventional group (online supplementary figure $\mathrm{S} 1$ ).

\section{DISCUSSION}

In this prospective observational study with drug-naïve patients with high $\mathrm{HbAlc}$, initial triple combination therapy of metformin, sitagliptin, and lobeglitazone showed better efficacy and safety profiles than the

Table 3 Variables associated with glycemic target goal ( $\mathrm{HbA} 1 \mathrm{c}<7.0 \%$ without hypoglycemia) at 12 months

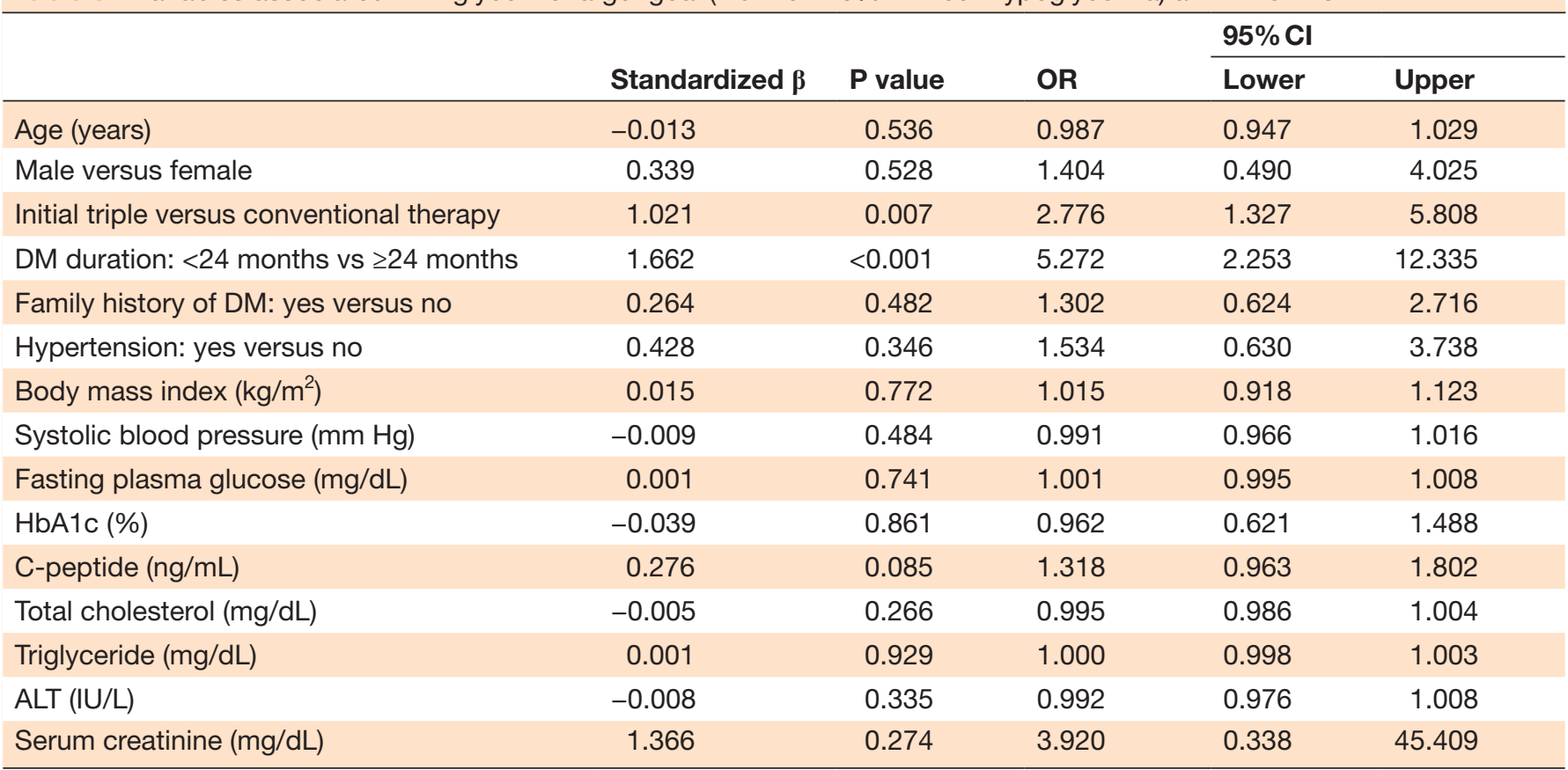

Multivariable logistic regression analysis was performed.

ALT, alanine aminotransferase; DM, diabetes mellitus. 
conventional stepwise approach with glimepiride and metformin. HbAlc was maintained at $<7.0 \%$ at 12 months by $69.8 \%$ of participants receiving triple therapy and $52.4 \%$ of participants receiving conventional therapy, which was significantly different. This difference became more obvious for the stricter target goal of $\mathrm{HbAl} c<6.5 \%$ $(58.1 \%$ vs $36.9 \%, \mathrm{p}<0.05)$.

After 12 months of treatment, significant improvement in surrogated markers related to insulin sensitivity and $\beta$-cell function was observed only in patients who received initial triple therapy. This result suggests that a proactive approach targeting pathophysiological defects of T2D using DPP4 inhibitor and TZD on top of metformin is a good option for management of T2D particularly in those with high HbA1c level at diagnosis.

In the conventional group treated with metformin and sulfonylurea, the QUICKI and Matsuda index scores increased significantly, which may indicate improvements in insulin sensitivity. By contrast, $\beta$-cell function estimated by HOMA- $\beta$ increased non-significantly in in this group. Considering that the HOMA-IR score was 5.7 and C-peptide level at baseline was $2.6 \mathrm{ng} / \mathrm{mL}$ in the conventional group, the study subjects seemed to have exhibited greater insulin resistance than a $\beta$-cell defect. This might be the reason for the lack of significant improvement in HOMA- $\beta$ in this group despite the significant decrease in HbA1c level. Metformin is known to decrease insulin resistance, but not to act on $\beta$-cells. Sulfonylurea is an insulin secretagogue, but it is not a drug that can improve $\beta$-cell function fundamentally.

A pathophysiological approach aiming to alleviate insulin resistance and hyperglucagonemia or to improve $\beta$-cell function has shown long-term benefit in T2D management, compared with simple insulin secretagogues. ${ }^{28-30}$ Here, both treatments showed substantial and comparable reductions in HbAlc levels during the first 5 months. However, hypoglycemia was reported in only one patient in the initial triple group, while 11 patients in the conventional group experienced hypoglycemia. Among them, one patient in the initial triple group and five in the conventional group discontinued the study because of hypoglycemia. High numbers of hypoglycemic events in the conventional therapy arm can be attributed to the uptitration of glimepiride or insulin, which was added as a rescue therapy.

The HbAlc levels in both groups were decreased significantly at the 2 and 5-month visits $(>2.0 \%$ and another $>1.0 \%$, respectively). The participants receiving initial triple combination therapy were able to maintain a target HbA1c goal of $<7.0 \%$ over 12 months (69.8\%). By contrast, the HbA1c level rebounded after 5 months using the stepwise approach. Only $52.4 \%$ of patients maintained the HbAlc target $<7.0 \%$ over 12 months. These results support the use of initial triple combination therapy with DPP4 inhibitor, metformin, and TZD for greater durability in glucose control than the stepwise therapy with metformin and sulfonylurea.
The $0.2 \%$ increasing tendency in HbA1c level after 5 months in our stepwise approach is consistent with data from previous studies with metformin, sulfonylurea, or insulin. ${ }^{12} 13{ }^{31}$ It should be noted that the progressive increase in $\mathrm{HbAlc}$ levels was paralleled by a progressive decline in $\beta$-cell function. ${ }^{11}$

At 12 months, $141 \mathrm{mg} / \mathrm{dL}$ of fasting plasma glucose (FPG) in the conventional group seemed not to be satisfactory but the metformin dose was not escalated to the maximum possible level; instead, $1425 \mathrm{mg}$ of metformin was used. High-dose metformin therapy is not generally prescribed in Asian countries because it tends to increase the incidence of adverse side effects, such as gastrointestinal discomfort, without affecting its glucose-lowering efficacy. ${ }^{32}$ Furthermore, high doses of metformin are also not recommended for elderly people because of their attenuated renal function. In our study, about $30 \%$ of the subjects were aged $>60$ years. For these reasons, a moderate dose of metformin (up to $\sim 1500 \mathrm{mg}$ ) was used in the conventional therapy group.

Theoretically, the combination of incretin-based therapy and TZD appears more ideal than either treatment alone, considering complementary mechanisms of action. To confirm this hypothesis, sitagliptin and lobeglitazone, a TZD, on top of metformin were chosen for a triple combination in the present study. In humans, initial combination treatment of sitagliptin and metformin showed larger improvements in glucose homeostasis and improvements in $\beta$-cell function than individual monotherapies for up to 2 years. ${ }^{33}$ We demonstrated that drug-naive patients with T2D benefited the most from early initial combination therapy of sitagliptin and metformin. ${ }^{34} 35$

In the present study, lobeglitazone was used as a TZD, which was developed aiming at a highly effective TZD with reduced side effects. Docking analysis for structural characteristics of TZD-bound PPAR- $\gamma$ suggested that lobeglitazone displays 12 times higher affinity to PPAR- $\gamma$ than rosiglitazone or pioglitazone. ${ }^{36}$

The results of the present study are consistent with previous work showing that metformin, pioglitazone, and exenatide triple combination therapy achieved an $\mathrm{HbAlc}$ target more successfully than in those receiving conventional therapy. ${ }^{17}$ However, it should be noted that adverse events related with exenatide injection were not negligible. The dropout rate in our triple group was much less than that observed in most studies with GLP1R agonists including exenatide ${ }^{37}$ and liraglutide.$^{38}$ Recently, SGLT2 inhibitors have proven cardiovascular and renal benefits in large cardiovascular outcome trials. ${ }^{39-41}$ Because SGLT2 inhibitors decrease body weight and blood pressure as well as glucose concentration, they might be another good agent for early combination.

In this study, the initial triple treatment involving a DPP4 inhibitor and a TZD decreased triglyceride and increased HDL-cholesterol levels. It alleviated albuminuria significantly, and improved liver enzyme activities compared with conventional treatment with metformin 
and sulfonylurea. These are additional advantages supporting an initial triple regimen for sulfonylureabased regimens.

Recent evidence has shown that hypoglycemia might be associated with higher mortality, ${ }^{42}$ and the American Diabetes Association and European Association for the Study of Diabetes have recommended less aggressive glucose control in individuals at high cardiovascular risk. ${ }^{6}$ In the present study, despite greater glucose lowering, the risk of hypoglycemia in the patients receiving initial triple therapy was one-fifth that in those receiving conventional therapy but is to be expected as conventional therapy included use of sulfonylureas known to significantly increase the risk of hypoglycemia. Drug compliance was higher in participants in the triple group than in those in conventional group, may be as a result of less hypoglycemia. Thus, initiation of a combination therapy with metformin, sitagliptin, and lobeglitazone produced greater and more durable HbA1c reductions and was safer with respect to hypoglycemia and other adverse events compared with a conventional stepwise approach with sulfonylureas and metformin.

The present study has several limitations. First, we did not use the same drugs and same drug number in the comparison, which prohibited complete blinding of the study. However, we wanted to compare the efficacy, safety, and durability of initial triple therapy including TZD and a DPP4 inhibitor, which might be an ideal combination, with those of conventional dose escalation approach with metformin and sulfonylurea. Second, because of the relatively small sample size and short duration, long-term outcome data were not available.

\section{CONCLUSIONS}

Initial combination treatment with metformin, sitagliptin, and lobeglitazone showed better efficacy and safety compared with a conventional stepwise approach of sequential dose escalation with metformin and sulfonylurea in drug-naïve patients with T2D with high baseline HbA1c levels. Additional advantages with regard to insulin sensitivity, $\beta$-cell function, lipid profiles, and albuminuria were also found in the triple therapy. The promising results observed in the present study require a larger multiethnic study with longer duration to validate our findings. Thus, initial triple combination therapy to preserve $\beta$-cells with a DPP4 inhibitor and to lower the burden of the $\beta$-cells with TZD and metformin might be an ideal option for drug-naïve patients with T2D with high HbA1c levels.

\footnotetext{
Author affiliations

${ }^{1}$ Department of Internal Medicine, Seoul National University College of Medicine and Seoul National University Bundang Hospital, Seongnam, South Korea ${ }^{2}$ Department of Internal Medicine, Chungbuk National University Hospital, Cheongju, South Korea

${ }^{3}$ Department of Internal Medicine, Mediplex Sejong Hospital, Incheon, South Korea ${ }^{4}$ Department of Internal Medicine, VHS Hospital, Seoul, South Korea

${ }^{5}$ Department of Internal Medicine, Hallym University Chuncheon Sacred Heart Hospital, Chuncheon, South Korea
}

${ }^{6}$ Diabetes Research Centre, University of Leicester, Leicester, UK

Contributors SL was a primary investigator, oversaw the conduct of the study, contributed to the acquisition and interpretation of the data, and wrote the manuscript. EJK, SYL, JHL, J-EL, KMK, and MJD participated in data interpretation and manuscript writing. SL is the guarantor of this work and, as such, has full access to all the data in the study and takes responsibility for the integrity of the data and the accuracy of the data analysis.

Funding This study was supported by Seoul National University Bundang Hospital. Competing interests None declared.

Patient consent for publication Not required.

Ethics approval The study was approved by the Institutional Review Board of Seoul National University Bundang Hospital (1010/115-008).

Provenance and peer review Not commissioned; externally peer reviewed.

Data availability statement Data are available upon reasonable request.

Open access This is an open access article distributed in accordance with the Creative Commons Attribution Non Commercial (CC BY-NC 4.0) license, which permits others to distribute, remix, adapt, build upon this work non-commercially, and license their derivative works on different terms, provided the original work is properly cited, appropriate credit is given, any changes made indicated, and the use is non-commercial. See: http://creativecommons.org/licenses/by-nc/4.0/.

ORCID IDs

Soo Lim http://orcid.org/0000-0002-4137-1671

Eu Jeong Ku http://orcid.org/0000-0001-5533-4989

\section{REFERENCES}

1 Gerstein HC, Miller ME, Byington RP, et al. Effects of intensive glucose lowering in type 2 diabetes. $N$ Engl $\mathrm{J} \mathrm{Med}$ 2008;358:2545-59.

2 Intensive blood-glucose control with sulphonylureas or insulin compared with conventional treatment and risk of complications in patients with type 2 diabetes (UKPDS 33). UK prospective diabetes study (UKPDS) group. Lancet 1998;352:837-53.

3 Nathan DM, Genuth S, Lachin J, et al. The effect of intensive treatment of diabetes on the development and progression of longterm complications in insulin-dependent diabetes mellitus. N Engl J Med 1993;329:977-86.

4 Holman RR, Paul SK, Bethel MA, et al. 10-Year follow-up of intensive glucose control in type 2 diabetes. N Engl J Med 2008;359:1577-89.

5 Davies MJ, D'Alessio DA, Fradkin J, et al. Management of hyperglycemia in type 2 diabetes, 2018. A consensus report by the American diabetes association (ADA) and the European association for the study of diabetes (EASD). Diabetes Care 2018:41:2669-701.

6 American Diabetes Association. 6. Glycemic Targets: Standards of Medical Care in Diabetes-2018. Diabetes Care 2018;41:S55-64.

7 Grunberger G, Handelsman Y, Bloomgarden ZT, et al. American association of clinical endocrinologists and American College of endocrinology 2018 position statement on integration of insulin pumps and continuous glucose monitoring in patients with diabetes mellitus. Endocr Pract 2018;24:302-8.

$8 \mathrm{Ko} \mathrm{SH}$, Hur KY, Rhee SY, et al. Antihyperglycemic agent therapy for adult patients with type 2 diabetes mellitus 2017: a position statement of the Korean diabetes association. Diabetes Metab J 2017;41:337-48.

9 Defronzo RA, Lecture B. Banting lecture. from the triumvirate to the ominous octet: a new paradigm for the treatment of type 2 diabetes mellitus. Diabetes 2009;58:773-95.

10 Moss SE, Klein R, Klein BE, et al. The association of glycemia and cause-specific mortality in a diabetic population. Arch Intern Med 1994;154:2473-9.

11 Turner RC, Cull CA, Frighi V, et al. Glycemic control with diet, sulfonylurea, metformin, or insulin in patients with type 2 diabetes mellitus: progressive requirement for multiple therapies (UKPDS 49). UK prospective diabetes study (UKPDS) group. JAMA 1999;281:2005-12.

12 Kahn SE, Haffner SM, Heise MA, et al. Glycemic durability of rosiglitazone, metformin, or glyburide monotherapy. N Engl J Med 2006;355:2427-43.

13 Mazzone T, Meyer PM, Feinstein SB, et al. Effect of pioglitazone compared with glimepiride on carotid intima-media thickness in type 2 diabetes: a randomized trial. JAMA 2006;296:2572-81. 
14 Ahmadian M, Suh JM, Hah N, et al. Ppary signaling and metabolism: the good, the bad and the future. Nat Med 2013;19:557-66.

15 Wu D, Li L, Liu C. Efficacy and safety of dipeptidyl peptidase-4 inhibitors and metformin as initial combination therapy and as monotherapy in patients with type 2 diabetes mellitus: a metaanalysis. Diabetes Obes Metab 2014;16:30-7.

16 Phung OJ, Sobieraj DM, Engel SS, et al. Early combination therapy for the treatment of type 2 diabetes mellitus: systematic review and meta-analysis. Diabetes Obes Metab 2014;16:410-7.

17 Abdul-Ghani MA, Puckett C, Triplitt C, et al. Initial combination therapy with metformin, pioglitazone and exenatide is more effective than sequential add-on therapy in subjects with new-onset diabetes. results from the efficacy and durability of initial combination therapy for type 2 diabetes (EDICT): a randomized trial. Diabetes Obes Metab 2015;17:268-75.

18 Plosker GL. Sitagliptin: a review of its use in patients with type 2 diabetes mellitus. Drugs 2014;74:223-42.

19 Jin S-M, Park C-Y, Cho YM, et al. Lobeglitazone and pioglitazone as add-ons to metformin for patients with type 2 diabetes: a 24-week, multicentre, randomized, double-blind, parallel-group, activecontrolled, phase III clinical trial with a 28-week extension. Diabetes Obes Metab 2015;17:599-602.

20 Matthews DR, Hosker JP, Rudenski AS, et al. Homeostasis model assessment: insulin resistance and beta-cell function from fasting plasma glucose and insulin concentrations in man. Diabetologia 1985;28:412-9.

21 Matsuda M, DeFronzo RA. Insulin sensitivity indices obtained from oral glucose tolerance testing: comparison with the euglycemic insulin clamp. Diabetes Care 1999;22:1462-70.

22 Katz A, Nambi SS, Mather K, et al. Quantitative insulin sensitivity check index: a simple, accurate method for assessing insulin sensitivity in humans. J Clin Endocrinol Metab 2000;85:2402-10.

23 Defronzo RA, Tripathy D, Schwenke DC, et al. Prediction of diabetes based on baseline metabolic characteristics in individuals at high risk. Diabetes Care 2013;36:3607-12.

24 Takahara M, Shiraiwa T, Matsuoka T-aki, et al. Ameliorated pancreatic $\beta$ cell dysfunction in type 2 diabetic patients treated with a sodium-glucose cotransporter 2 inhibitor ipragliflozin. Endocr J 2015;62:77-86.

25 Wareham NJ, Phillips DI, Byrne CD, et al. The 30 minute insulin incremental response in an oral glucose tolerance test as a measure of insulin secretion. Diabet Med 1995;12:931.

26 Stumvoll M, Mitrakou A, Pimenta W, et al. Use of the oral glucose tolerance test to assess insulin release and insulin sensitivity. Diabetes Care 2000;23:295-301.

27 Dormandy JA, Charbonnel B, Eckland DJA, et al. Secondary prevention of macroVascular events in patients with type 2 diabetes in the proactive study (prospective pioglitAzone clinical trial in macroVascular events): a randomised controlled trial. Lancet 2005;366:1279-89.
28 Bunck MC, Cornér A, Eliasson B, et al. Effects of exenatide on measures of $\beta$-cell function after 3 years in metformin-treated patients with type 2 diabetes. Diabetes Care 2011;34:2041-7.

29 Rasouli N, Kern PA, Reece EA, et al. Effects of pioglitazone and metformin on beta-cell function in nondiabetic subjects at high risk for type 2 diabetes. Am J Physiol Endocrinol Metab 2007;292:E359-65.

30 Xiang AH, Peters RK, Kjos SL, et al. Effect of pioglitazone on pancreatic beta-cell function and diabetes risk in Hispanic women with prior gestational diabetes. Diabetes 2006;55:517-22.

31 Brown JB, Conner C, Nichols GA. Secondary failure of metformin monotherapy in clinical practice. Diabetes Care 2010;33:501-6.

32 Dujic T, Zhou K, Donnelly LA, et al. Association of organic cation transporter 1 with intolerance to metformin in type 2 diabetes: a GoDARTS study. Diabetes 2015;64:1786-93.

33 Williams-Herman D, Xu L, Teng R, et al. Effect of initial combination therapy with sitagliptin and metformin on $\beta$-cell function in patients with type 2 diabetes. Diabetes Obes Metab 2012;14:67-76.

$34 \mathrm{Lim} \mathrm{S}, \mathrm{An} \mathrm{JH}$, Shin $\mathrm{H}$, et al. Factors predicting therapeutic efficacy of combination treatment with sitagliptin and metformin in type 2 diabetic patients: the cosmetic study. Clin Endocrinol 2012;77:215-23.

$35 \mathrm{Ku}$ EJ, Jung KY, Kim YJ, et al. Four-Year durability of initial combination therapy with sitagliptin and metformin in patients with type 2 diabetes in clinical practice; COSMIC study. PLoS One 2015;10:e0129477.

36 Lee MA, Tan L, Yang H, et al. Structures of PPAR $\gamma$ complexed with lobeglitazone and pioglitazone reveal key determinants for the recognition of antidiabetic drugs. Sci Rep 2017;7:16837.

37 Gallwitz B, Guzman J, Dotta F, et al. Exenatide twice daily versus glimepiride for prevention of glycaemic deterioration in patients with type 2 diabetes with metformin failure (EUREXA): an open-label, randomised controlled trial. Lancet 2012;379:2270-8.

38 Pratley RE, Nauck MA, Bailey T, et al. Efficacy and safety of switching from the DPP-4 inhibitor sitagliptin to the human GLP-1 analog liraglutide after 52 weeks in metformin-treated patients with type 2 diabetes: a randomized, open-label trial. Diabetes Care 2012;35:1986-93.

39 Neal B, Perkovic V, Mahaffey KW, et al. Canagliflozin and cardiovascular and renal events in type 2 diabetes. $N$ Engl $\mathrm{J}$ Med 2017;377:644-57.

40 Wiviott SD, Raz I, Bonaca MP, et al. Dapagliflozin and cardiovascular outcomes in type 2 diabetes. N Engl J Med 2019;380:347-57.

41 Zinman B, Wanner C, Lachin JM, et al. Empagliflozin, cardiovascular outcomes, and mortality in type 2 diabetes. $N$ Engl J Med 2015;373:2117-28.

42 Seaquist ER, Anderson J, Childs B, et al. Hypoglycemia and diabetes: a report of a Workgroup of the American diabetes association and the endocrine Society. Diabetes Care 2013:36:1384-95. 